\title{
1 Biocatalytic Construction of Quaternary Centers by Aldol Addition of 3,3-Disubstituted 2-Oxoacid Derivatives to Aldehydes
}

\author{
3 Roser Marín-Valls, ${ }^{\perp}$ Karel Hernández, ${ }^{\perp}$ Michael Bolte, Teodor Parella, Jesús Joglar, Jordi Bujons, \\ 4 and Pere Clapés*
}

\begin{abstract}
| $\mid$
5 ABSTRACT: The congested nature of quaternary carbons hinders their preparation, 6 most notably when stereocontrol is required. Here we report a biocatalytic method for 7 the creation of quaternary carbon centers with broad substrate scope, leading to 8 different compound classes bearing this structural feature. The key step comprises the 9 aldol addition of 3,3-disubstituted 2-oxoacids to aldehydes catalyzed by metal 10 dependent 3-methyl-2-oxobutanoate hydroxymethyltransferase from E. coli 11 (KPHMT) and variants thereof. The 3,3,3-trisubstituted 2-oxoacids thus produced 12 were converted into 2-oxolactones and 3-hydroxy acids and directly to ulosonic acid 13 derivatives, all bearing gem-dialkyl, gem-cycloalkyl, and spirocyclic quaternary centers. In 14 addition, some of these reactions use a single enantiomer from racemic nucleophiles to 15 afford stereopure quaternary carbons. The notable substrate tolerance and stereocontrol 16 of these enzymes are indicative of their potential for the synthesis of structurally 17 intricate molecules.
\end{abstract}

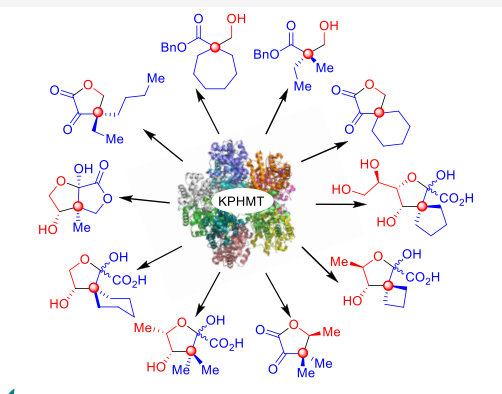

$\checkmark$ Enzymatic construction of quaternary carbon centers. Broad substrate scope.

$\checkmark$ Stereocontrol.
19 Quaternary centers are important structural units that can be 20 found in naturally occurring, biologically active compounds 21 and pharmaceutical ingredients (Figure 1). ${ }^{1}$ Bioactive mole22 cules bearing this feature are becoming most appreciated in 23 medicinal chemistry because they (i) expand the chemical

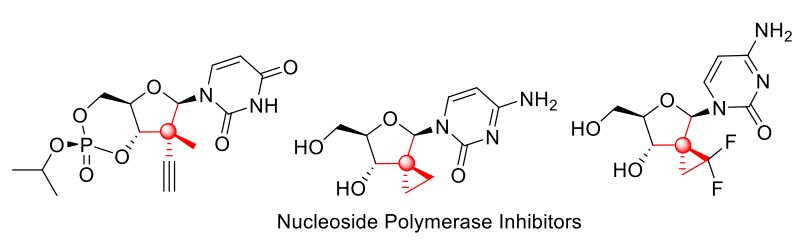

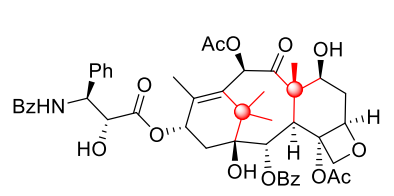

Paclitaxel Anticancer

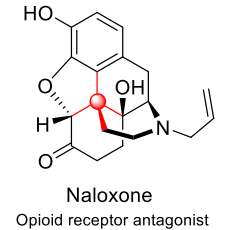

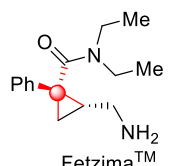

Fetzima $^{\text {TM }}$

Galantamine Alzheimer disease Depressive disorders

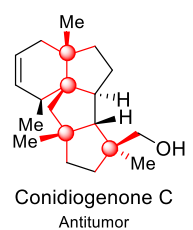

Figure 1. Examples of bioactive molecules and pharmaceuticals bearing quaternary centers. diversity besides the heteroaromatic "flat" chemistry, (ii) 24 enhance the binding selectivity with target proteins avoiding 25 unspecific interactions (e.g., $\pi$-staking), and (iii) have better 26 solubility and bioavailability. ${ }^{2}$

Therefore, synthetic access to this type of compound can be 28 regarded as significant and a challenging task for organic 29 chemists. Indeed, creation of quaternary stereocenters is 30 elusive mainly due to the steric hindrance between the carbon 31 substituents, and consequently, considerable efforts have been 32 dedicated to implement chemical methodologies for this 33 purpose. ${ }^{1 \mathrm{a}, \mathrm{g}, 3}$ These encompass long-established approaches 34 such as Claisen rearrangement ${ }^{4}$ and Diels-Alder reaction ${ }^{5}$ up 35 to the most recent ones based on transition metal 36 catalysis $^{1 \mathrm{c}, 2 \mathrm{~b}, 3 \mathrm{e}, 6}$ and organocatalytic reactions. ${ }^{3 \mathrm{k}, 7}$ However, 37 innovative procedures expanding the range of structurally 38 diverse products with improved efficacy, simplicity, and 39 stereoselectivity are key for advancing the field of chemical 40 synthesis. ${ }^{6 c, 8}$

Biocatalytic creation of carbon-carbon bonds is widely 42 recognized as a useful synthetic technology particularly 43 because of its high selectivity, mild operation conditions, and 44 use of simple starting materials in a straightforward fashion. ${ }^{9} 45$

Received: September 18, 2020 
46 Furthermore, biocatalysis is accepted as a green and sustainable 47 technology. ${ }^{10}$ However, enzymatic methods to forge quater48 nary carbon stereocenters are scarce. ${ }^{11}$

49 In this work, we explored the capabilities of metal-dependent 50 3-methyl-2-oxobutanoate hydroxymethyltransferase (KPHMT, 51 EC 2.1.2.11) from E. coli and its variants to catalyze the 52 formation of quaternary centers. In vivo, KPHMT catalyzes the 53 transfer of the hydroxymethyl group from $N,{ }^{5} N^{10}$-methylene 54 tetrahydrofolate (MTHF) to 2-oxoisovalerate (2-OI) to 55 produce ketopantoate (KP), bearing a gem-dimethyl quater56 nary center and tetrahydrofolate (THF) (Scheme 1). ${ }^{12}$ It has

Scheme 1. 3-Methyl-2-oxobutanoate

Hydroxymethyltransferase (KPHMT) Catalyzed the Synthesis of Ketopantoate (KP), a Precursor of Vitamin $\mathrm{B5}^{a}$

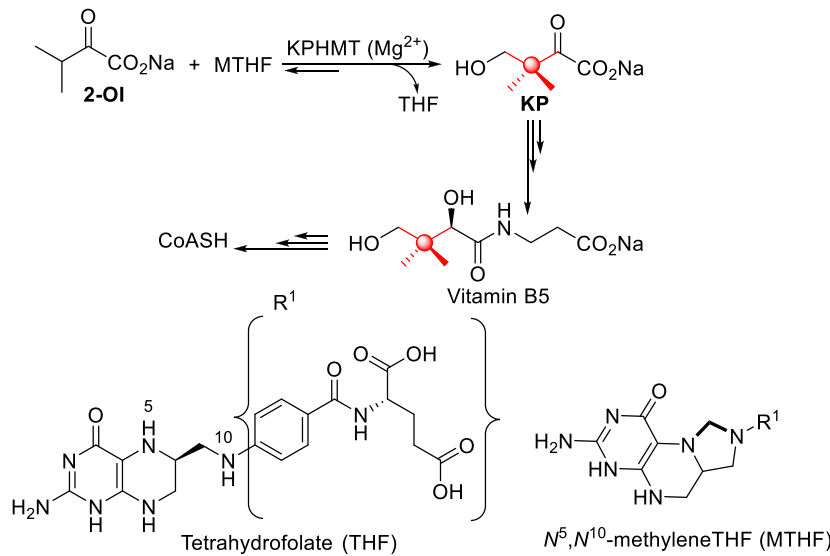

${ }^{a} \mathrm{MTHF}=N^{5}, N^{10}$-methylene tetrahydrofolate; THF = tetrahydrofolate. $\mathrm{CoASH}=$ Coenzyme A. ${ }^{14}$

57 also been found that KPHMT can function as a metal58 dependent (Class II) aldolase, catalyzing the aldol addition of 59 2-oxoacids to methanal and operating under a tetrahydrofolate60 independent mechanism. ${ }^{13}$ Indeed, the enzyme is able to 61 catalyze the enolization of the 2 -oxoacid via an $\alpha$-proton 62 abstraction and formation of the corresponding stabilized 63 carbanion. This enolate can attack the methylene group of $64 \mathrm{MTHF}$, resulting in the formation of $\mathrm{KP}$, in vivo activity, or 65 eventually on other electrophiles, e.g., aldehydes. ${ }^{13 a}$

\section{RESULTS AND DISCUSSION}

67 In a previous work, we reported on the preparation of 2 68 substituted 3-hydroxycarboxylic esters from 3-monosubstituted 69 2-oxoacids and methanal. ${ }^{13 b}$ Here, we investigated the aldol 70 addition of 3,3-disubstituted 2-oxoacids (1) to diverse 71 aldehyde (2), mediated by KPHMT catalysts, to generate 72 3,3,3-trisubstituted 2-oxoacids (3) bearing a quaternary 73 stereocenter (Scheme 2).

74 To establish optimal KPHMT catalysts, we capitalize on the 75 recently engineered KPHMT variants I212A and I202A, which 76 tolerate 3-monosubstituted 2-oxoacids with linear, branched, 77 or cyclic substituents. ${ }^{13 \mathrm{~b}}$ Furthermore, based on the KPHMT 78 structure (Figure 2A), we envisioned that residues I212, I202, 79 as well as V214 could also be involved in the accommodation 80 of the tertiary carbon nucleophiles (i.e., 3,3-disubstituted 281 oxoacids). ${ }^{13 \mathrm{~b}}$ Molecular models of variants at these positions 82 showed larger active sites that could accommodate the 83 sterically hindered nucleophiles considered (Figure 2 and
Scheme 2. Selected Panel of 3,3-Disubstituted 2-Oxoacids (1) and Aldehydes (2) as Substrates for KPHMT-Catalyzed Formation of Quaternary Carbon Centers by Aldol Addition Reactions

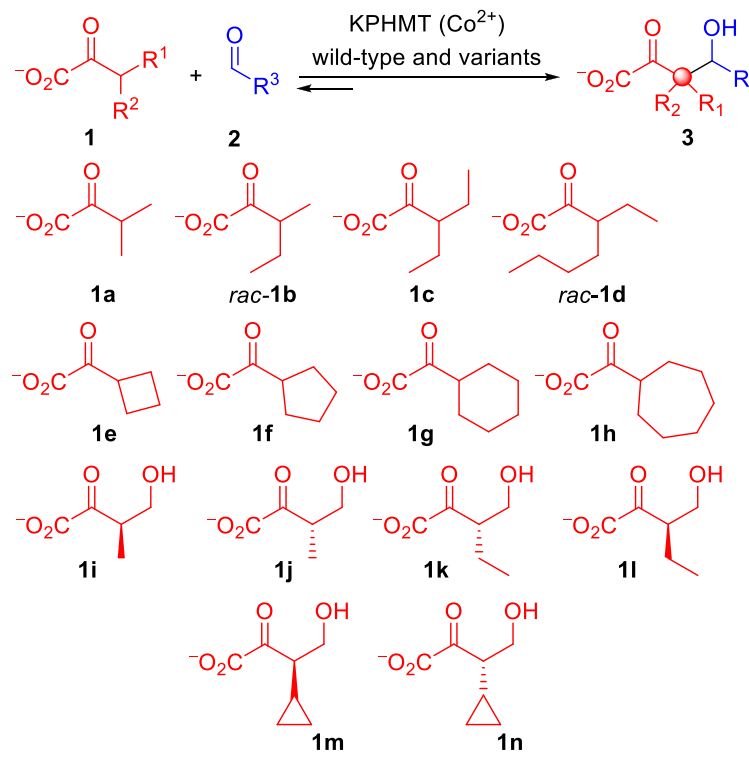<smiles></smiles>

Figures S117-S128). Thus, seven KPHMT variants, i.e., 84 I212A, I202A, V214G, I202A/I212A, I202A/V214G, I212A/ 85 V214G, and I202A/I212A/V214G, were constructed and 86 tested as biocatalysts. Notably, the enzymes were obtained in 87 high yields after expression and purification (88-205 $\mathrm{mg}$ of 88 protein per liter of medium culture, see SI). Purified KPHMT 89 catalysts were stored and used in the reactions as glycerinate 90 preparations (i.e., a solution of the enzyme consisting of 2091 mM MOPS buffer $\mathrm{pH} 7.0$ containing $\mathrm{NaCl}(50 \mathrm{mM})$ and 92 glycerol $(50 \%))$. Furthermore, we previously found that 93 KPHMT catalysts with $\mathrm{Co}^{2+}$ as metal cofactor gave the best 94 activity. ${ }^{13 \mathrm{~b}}$ Therefore, we decided to employ $\mathrm{Co}^{2+}$ as a cofactor 95 for all KPHMT catalysts in this work.

Screening of KPHMT Catalysts and Substrates. We 97 began our investigation on the screening of the KPHMT 98 catalysts assaying the panel of nucleophiles and electrophiles 99 for measuring the formation of aldol products 3 and/or 100 consumption of substrates after $24 \mathrm{~h}$ (Figure 3, see SI) and $101 \mathrm{f} 3$ reaction rates $\left(v_{0}\right)$ (Figures $\mathrm{S} 74$ and $\mathrm{S} 75$ ).

102

Despite that wild-type KPHMT efficiently catalyzed the 103 aldol reaction in some cases, variants I202A, I212A, and the 104 double variant I202A/I212A gave the best ( $\geq 90 \%)$ con- 105 versions for most of the reactions and variant V214G 106 specifically for the addition of $\mathbf{1 a}$ to $\mathbf{2 h}$. Several KPHMT 107 variants gave conversions $\geq 60 \%$ with combinations of 108 nucleophiles 1a, 1e, and 1f with electrophiles 2a-h. 109 Exceptions were $\mathbf{2 b}+\mathbf{1 f}(50 \%)$ and $\mathbf{2 d}+\mathbf{1 f}$ (28\%). 2-Oxoacids 110 $\mathbf{1 g}$ and $\mathbf{1 h}$ were substrates when methanal (2a) (20 and $40 \% 111$ with variants $\mathrm{I} 212 \mathrm{~A}$ and $\mathrm{I} 202 \mathrm{~A} / \mathrm{I} 212 \mathrm{~A}$, respectively) and 2- 112 


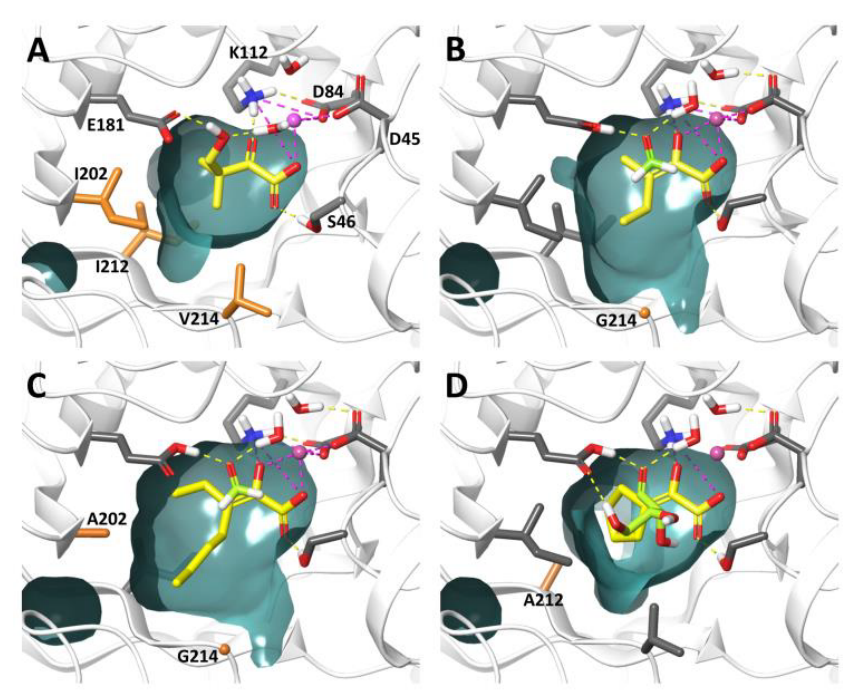

Figure 2. (A) Structure of the active site of the ketopantoate complex of wild-type KPHMT (chain A, PDB 1M3U). ${ }^{15}$ Ketopantoate is shown with yellow $\mathrm{C}$ atoms, and the three residues proposed for mutation are shown with orange $\mathrm{C}$ atoms. Models of the prereactive complexes of (B) KPHMT V214G with (S)-1b and 2a, (C) KPHMT I202A/V214G with (S)-1d and 2a, and (D) KPHMT I212A with 1f and $\mathbf{2 h}$. Nucleophiles $\mathbf{1 b}, \mathbf{1 d}$, and $\mathbf{1 f}$ are shown with yellow $\mathrm{C}$ atoms, electrophiles $\mathbf{2 a}$ and $\mathbf{2 h}$ with green $\mathrm{C}$ atoms, and the mutated residues with orange $\mathrm{C}$ atoms. Nucleophiles are shown in their enolate form (1b and $\mathbf{1 d}$ as E-enolates) coordinated to the metal cofactor (purple sphere), which is also coordinated by residues D45 and D84 and by two water molecules. $\mathbf{2 a}$ and $\mathbf{2 h}$ are displayed with their carbonyl oxygen atom forming hydrogen bonds with residue E181 and one of the metal-coordinated waters. $\mathbf{2 h}$ is shown approaching the enolate from its $s i$-face. The surfaces of the active site cavities near the nucleophile substrates are shown in cyan. Interactions are shown with dashed lines: H-bond in yellow, salt bridges in magenta.

113 hydroxyethanal (2c) (50 and 42\%, respectively, with I212A) 114 were used as electrophiles, whereas they were not converted 115 using $\mathbf{2 b}$ and $\mathbf{2 e}-\mathbf{h}$. Nucleophiles $\mathbf{1 m}-\mathbf{n}$ and electrophiles $\mathbf{2 i}-$ $116 \mathbf{~ k}$ were not converted by any KPHMT catalysts. The results are 117 consistent with the initial reaction rates $\left(v_{0}\right)$ of the 118 corresponding reactions (Figures S74 and S75). Notably, $119 \operatorname{KPHMT}\left(\mathrm{Co}^{2+}\right)$ catalyst loading was $0.068 \mathrm{~mol} \%$. This 120 catalytic efficiency in addition to their high expression levels 121 make these enzymes highly valuable for preparative-scale 122 synthesis.

123 Preparative Synthesis. The positive reactions were run at 124 a preparative scale $(2.5 \mathrm{mmol}$ of the limiting 3,3-disubstituted 1252 -oxoacid (1) substrate), providing, after the adequate 126 treatment (see below), the corresponding 2-oxolactones $127(\mathbf{4 a - g})$ (Scheme 3A), 3-hydroxy acid derivatives $(\mathbf{5 a}-\mathbf{j})$ 128 (Scheme 3B), bicyclic lactones (6) (Scheme 4A), and ulosonic 129 acid type products $(7 \mathbf{a}-\mathbf{q})$ (Scheme 4B), all of them bearing $130 \mathrm{gem}$-dialkyl, gem-cycloalkyl, and spirocyclic quaternary centers, 131 with final product amounts ranging from 50 to $390 \mathrm{mg}$. The 2132 oxolactones $4 \mathbf{a}-\mathbf{g}$ were produced during workup (acidic 133 aqueous-organic solvent extraction). Thus, when quantitative 134 conversions were achieved, this methodology was enough to 135 afford pure material (Scheme 3A). Otherwise, an additional 136 extraction with aqueous buffer at neutral $\mathrm{pH}$ removed the 137 remaining starting 2-oxoacid $\mathbf{1}$, which was the main impurity 138 present. The 2-oxo group can be reduced, ${ }^{16}$ affording $\alpha$ 139 hydroxy- $\gamma$-butyrolactones (e.g., $(R)$ - or $(S)$-pantolactone and

analogues), chiral auxiliaries, and important precursors for the 140 synthesis of naturally occurring and synthetic biologically 141 active compounds. ${ }^{17}$ Elaborated chemical transformations on 142 the carboxylate group such as oxidative decarboxylation 143 followed by esterification lead to different 3-hydroxyesters 144 (5a-i and amide 5j, Scheme 3B) with application as building 145 blocks in the synthesis of pharmaceutical compounds ${ }^{18}$ and 146 polymers, coating oligomers, and dendrimers, e.g., 2,2- 147 bis(hydroxymethyl) propionic acid derivative 5g. ${ }^{19} \quad 148$

Using 2-hydroxyaldehydes, $\mathbf{2} \mathbf{c}$ and $\mathbf{2 e - h}$, as electrophiles, 149 the spontaneous formation of cyclic hemiketals effectively 150 shifted the reaction equilibrium to the aldol products $6 \mathbf{a}, \mathbf{b}$ and 151 $7 \mathbf{a}-\mathbf{q}$ (Scheme 4A,B). The resulting adduct products were 152 easily purified by anion exchange chromatography, eluting with 153 formic acid. These ulosonic acid type products, bearing a 154 quaternary center at $\mathrm{C} 3$, have not been hitherto reported, and 155 their preparation using conventional chemical procedures may 156 be anticipated to be elusive because of the number of 157 functional groups and the intrinsic reactivity of the 2-oxoacid 158 moiety. ${ }^{20}$ Furthermore, KPHMT would facilitate access to a 159 great variety of ulosonic acids (e.g., sialic acid family), which 160 constitute important biologically active compounds involved in 161 cellular recognition and communication. ${ }^{21} \quad 162$

The addition of $1 \mathbf{j}$ to $2 \mathrm{c}$ (Scheme $4 \mathrm{~A}$ ) gave a mixture of the 163 two diastereomeric lactones $\mathbf{6 a}$ and $\mathbf{6 b}$ (91:9, respectively), 164 identified by NMR after anion exchange purification. The 165 acidic elution conditions (i.e., $\mathrm{HCOOH}, 1 \mathrm{M}$ ) and the 166 
Scheme 3. General Routes for the Synthesis of Products 4 (A) and 5 (B)
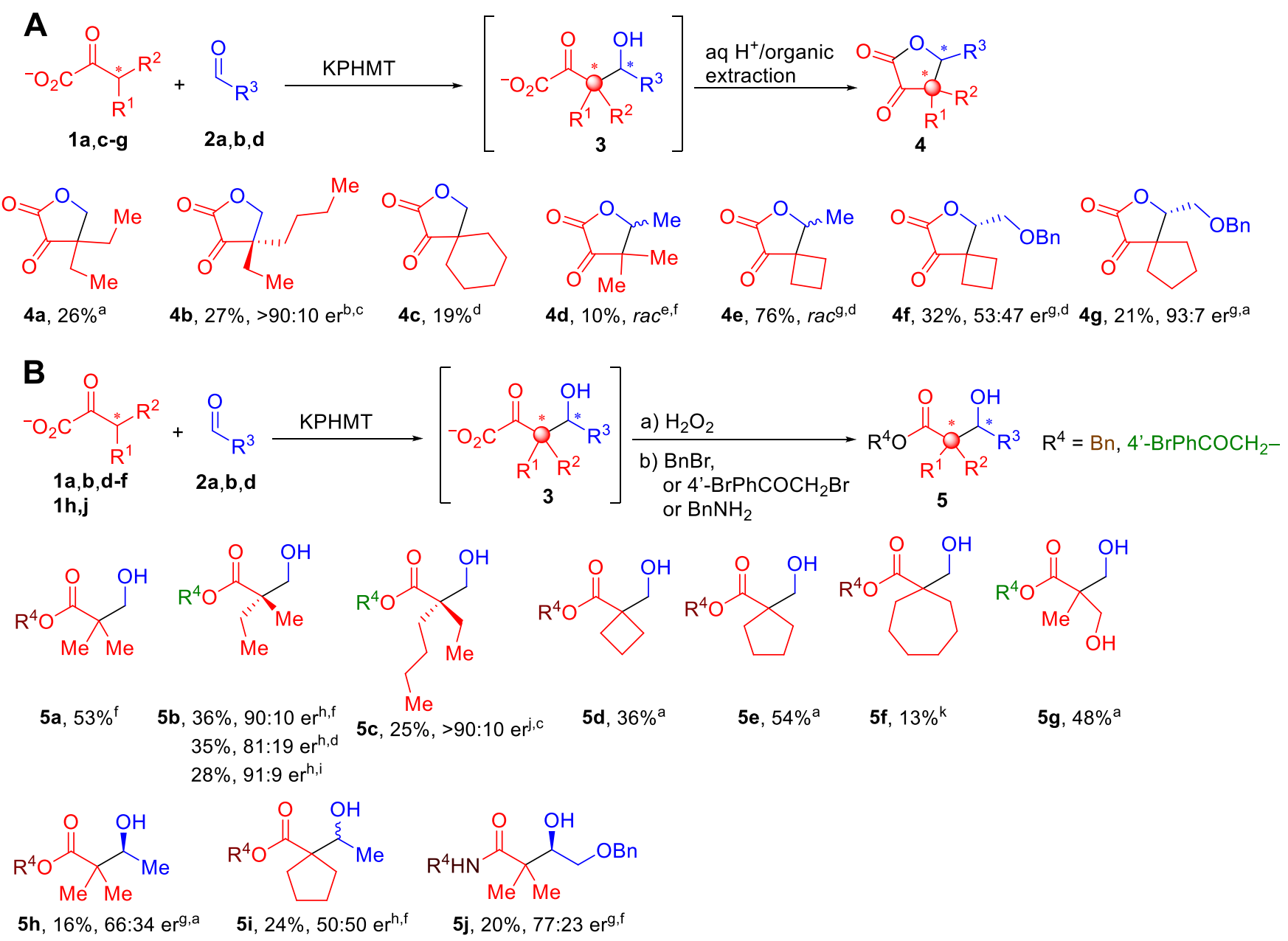

${ }^{a}$ I202A. ${ }^{b}$ Absolute stereochemistry assigned on the basis of crystal X-ray diffraction of compound 5c. ${ }^{c}$ I202A/V214G. ${ }^{d}$ I212A. ${ }^{e}$ Not determined. For optical rotations see SI. ${ }^{f}$ Wild-type. ${ }^{g}$ Enantiomeric ratio determined by NMR using $R$-configured Pirkle's alcohol. ${ }^{22}{ }^{h}$ Enantiomeric ratio determined by HPLC on the chiral stationary phase. ${ }^{i} \mathrm{~V} 214 \mathrm{G},{ }^{j}$ The absolute stereochemistry was determined by single-crystal X-ray diffraction (see SI). ${ }^{k}$ I202A/I212A. ${ }^{a, c, d, f, i, k}$ Catalyzed by $0.068 \mathrm{~mol} \%$ of $\operatorname{KPHMT}\left(\mathrm{Co}^{2+}\right)$ wild-type or variants thereof.

167 lyophilization of the fraction pool promoted the lactonization 168 of the hemiketal intermediate.

169 The absolute stereochemistry of $4 \mathbf{f}-\mathbf{g}$ and $7 \mathbf{a}-\mathbf{e}$ was 170 assigned by comparing the stereochemical outcome achieved 171 for $7 \mathbf{f}-\mathbf{q}$. Compounds $7 \mathbf{f}-\mathbf{q}$ contain one or two chiral centers 172 of defined absolute configuration that act as a reference in the 173 determination of their overall relative configuration. In $7 \mathbf{f}-\mathbf{q}$ 174 the absolute stereochemistry of the chiral center coming for 175 the electrophile was invariably $S$ regardless of the aldehyde 176 substrate. This is also consistent with a previous study on the 177 steric course of KPHMT-catalyzed aldol reaction with 178 MTHF. $^{23}$ Therefore, it may safely be assumed that the major 179 enantiomer of $\mathbf{4 f}-\mathbf{g}, 7 \mathbf{a}-\mathbf{e}$, and $\mathbf{5 h}$ will be $S$, and that of $\mathbf{5 j}$ will 180 be $R$ configured. The absolute stereochemistry of $\mathbf{5 b}$ was 181 assessed indirectly by analyzing the stereochemistry of the 182 unreacted $\mathbf{1 b}$. This was determined to be $R$ configured 183 according to chiral HPLC analysis against a standard (see 184 Figure S77). This indicated that only the corresponding 185 enantiomer $S$-1b was converted. From mechanistic consid186 erations of KPHMT catalysis (see below and Scheme 5), it 187 may be inferred that the $S-\mathbf{1 b}$ furnished $S-\mathbf{5 b}$. The X-ray diffraction provided the absolute $S$-configuration of 5c (Figure 188 S79) that agrees with the $S$-5b stereochemistry. 189

The $S$-configured $\mathbf{5 b}$ and $\mathbf{5 c}$ could be rationalized based on 190 the molecular models shown in panels B and C of Figure 2. To 191 form the corresponding enolates, nucleophiles 1 should adopt 192 a bound orientation in the catalytic site with their $\mathrm{H}$ atom at 193 C3 oriented toward the proposed catalytic base (E181). ${ }^{15} 194$ Therefore, it could be reasoned that the $S$-enantiomer of $\mathbf{1 b} 195$ can adopt an appropriate conformation with minimal steric 196 repulsion for its C3-ethyl substituent (Scheme 5). The 197 corresponding $E$-enolate would then expose its $r$ face to the 198 electrophile (Figure 2B), providing the 3S-aldol adduct, a 199 precursor of $S-5 \mathbf{b}$. In contrast, $R-\mathbf{1} \mathbf{b}$ has to adopt a different 200 bound conformation, with its C3-ethyl substituent pointing 201 toward residue V179, in order to place its $\alpha$-proton within 202 reach of the catalytic base (Scheme 5). This conformation, 203 which is less favored because of the proximity of the ethyl 204 moiety to the side chains of V179 and E181, would generate a 205 $Z$-enolate that would expose its $s i$-face to the electrophile, 206 providing the alternative $3 R$-aldol adduct. Similarly, each 207 enantiomer of nucleophile $\mathbf{1 d}$ can only adopt one reactive 208 conformation that would generate the corresponding $E$ - and Z- 209 
Scheme 4. General Routes for the Synthesis and Isolation of Products 6 and 7

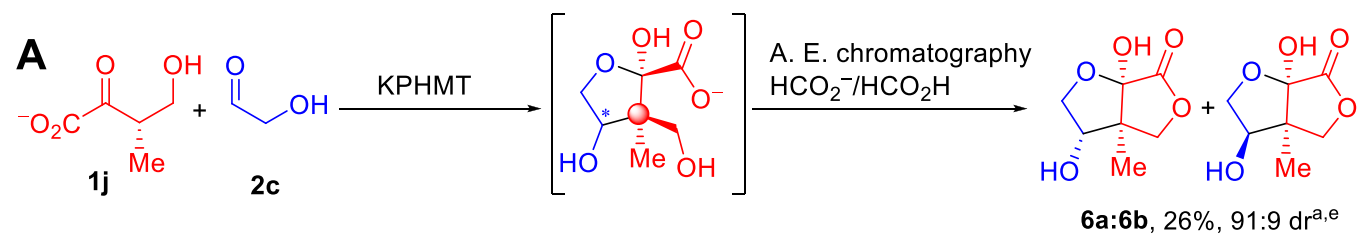

B
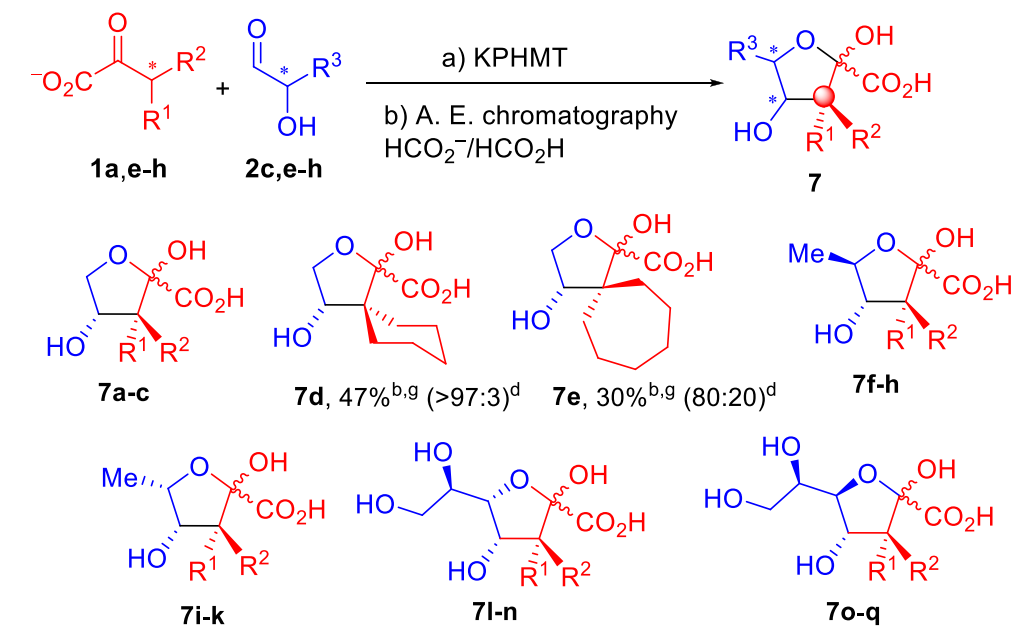<smiles>[R]C1[C@H](O)[C@@H]([C@H](O)CO)O[C@]1(O)C(=O)O</smiles>

\begin{tabular}{|c|c|c|c|c|c|}
\hline $\mathrm{R}^{1}=\mathrm{R}^{2}$ & & & & & \\
\hline \multirow[t]{2}{*}{$-\mathrm{CH}_{3}$} & $7 \mathrm{a} 87 \%^{\mathrm{b}, \mathrm{f}}$ & $7 f \quad 61 \%{ }^{c, e}$ & $7 \mathrm{i} 72 \%^{\mathrm{c}, e}$ & $7 \mathrm{I} 81 \%^{\mathrm{c}, \mathrm{e}}$ & $7080 \%{ }^{c, h}$ \\
\hline & $(60: 40)^{d}$ & $(26: 74)^{d}$ & $(21: 79)^{d}$ & $(76: 24)^{d}$ & $(24: 76)^{d}$ \\
\hline \multirow[t]{2}{*}{$-\left(\mathrm{CH}_{2}\right)_{3^{-}}$} & $7 \mathrm{~b} 90 \%{ }^{\mathrm{b}, \mathrm{e}}$ & $7 \mathrm{~g} 72 \%^{\mathrm{c}, \mathrm{g}}$ & $7 \mathbf{j} 77 \%{ }^{\mathrm{c}, \mathrm{g}}$ & $7 \mathrm{~m} 91 \%^{\mathrm{c}, \mathrm{g}}$ & $7 p 88 \%$ c,g \\
\hline & $(60: 40)^{d}$ & $(42: 58)^{d}$ & $(45: 55)^{d}$ & $(56: 44)^{d}$ & $(50: 50)^{d}$ \\
\hline \multirow[t]{2}{*}{$-\left(\mathrm{CH}_{2}\right)_{4^{-}}$} & $7 c 76 \%{ }^{b, f}$ & 7h $50 \%{ }^{c, g}$ & $7 \mathrm{k} 65 \%^{\mathrm{c}, \mathrm{g}}$ & 7n $73 \%^{c, g}$ & $7 q 48 \%$ c,g \\
\hline & $(77: 23)^{d}$ & $(37: 63)^{d}$ & $(10: 90)^{d}$ & $(76: 24)^{d}$ & $(50: 50)^{d}$ \\
\hline
\end{tabular}

${ }^{a}$ Measured by NMR. ${ }^{b}$ Not determined. For optical rotations, see SI. ${ }^{c}$ No other diastereomers were detected by NMR analysis. ${ }^{d} \alpha: \beta$ anomeric ratio. ${ }^{e-h}$ Catalyzed by $0.068 \mathrm{~mol} \%$ of: ${ }^{e}$ wild-type $\operatorname{KPHMT}\left(\mathrm{Co}^{2+}\right)$, or variants ${ }^{f}$ I202A. ${ }^{g}$ I212A. ${ }^{h}$ V214G.

\section{Scheme 5. Enolization Mechanism of Nucleophiles $S-1 b, d$ and $R-1 b, d$}
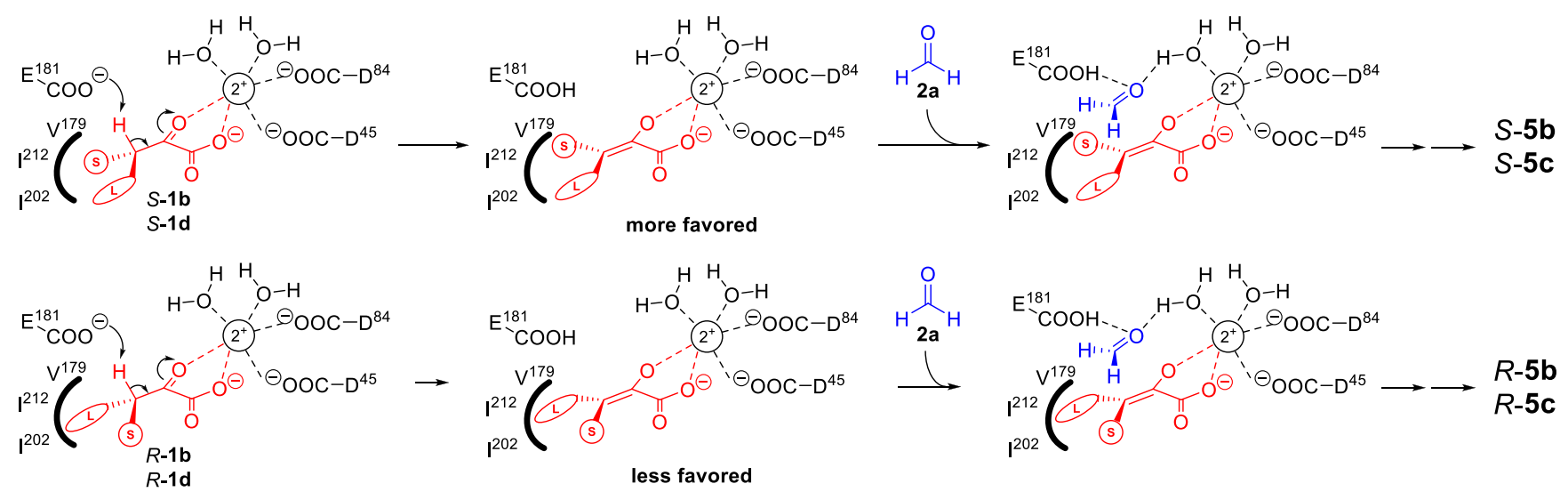

(L) = large substituent 1b: $-\mathrm{CH}_{2} \mathrm{CH}_{3} ; \mathbf{1 d}:-\mathrm{CH}_{2} \mathrm{CH}_{2} \mathrm{CH}_{2} \mathrm{CH}_{3}$

(s) = small substituent $1 \mathbf{b}:-\mathrm{CH}_{3} ; \mathbf{1 d}:-\mathrm{CH}_{2} \mathrm{CH}_{3}$

210 enolates (Figure 2C), from $S$ - and $R$-1d, respectively. Due to 211 the larger size of the $n$-butyl C3-substituent, formation of the 212 E-enolate would be faster, and consequently, the $3 S$-aldol 213 adduct is formed preferentially. Similar reasoning could be 214 used to explain the steric outcome observed for the rest of the 215 products (see SI).
In some cases, minor cyclic structures such as 2-oxolactone $\mathbf{8} 216$ and the corresponding hydrated form 9 (Scheme 6 and spectra $217 \mathrm{~s} 6$ in SI) were identified. It is likely that the purification process 218 under acid conditions and freeze drying favored the formation 219 of these side derivatives.

220

The addition of $\mathbf{1 a}, \mathbf{1 e}$, and $\mathbf{1 f}$ to D-threose was planned as a 221 simultaneous biocatalytic one-pot two-step cascade reaction $222 \mathrm{~s} 7$ 
Scheme 6. Equilibrium between Lactones 8 and 9 and Hemiketal 7 in Acidic Aqueous Medium

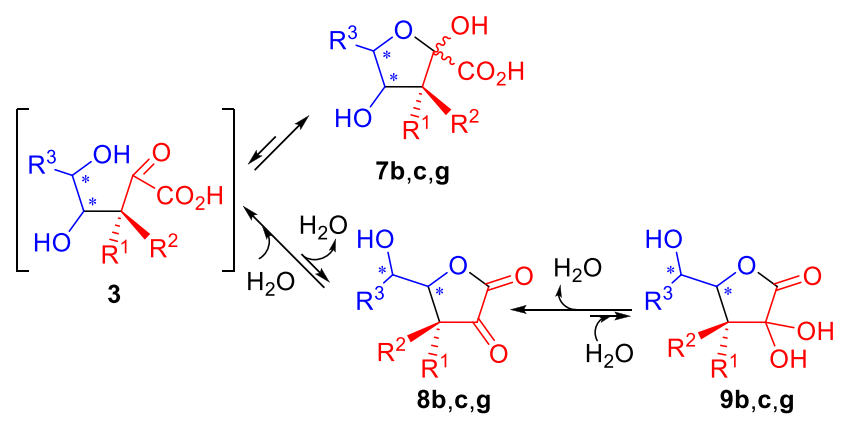

223 (Scheme 7A). To this end, D-threose $(\mathbf{2 g})$ was first produced 224 by enzymatic homoaldol addition of hydroxyethanal (2c)

Scheme 7. One-Pot Two-Step Enzymatic Synthesis of Products 71 (A) and the Diasteromeric Mixture 6a:6b (B) ${ }^{a}$
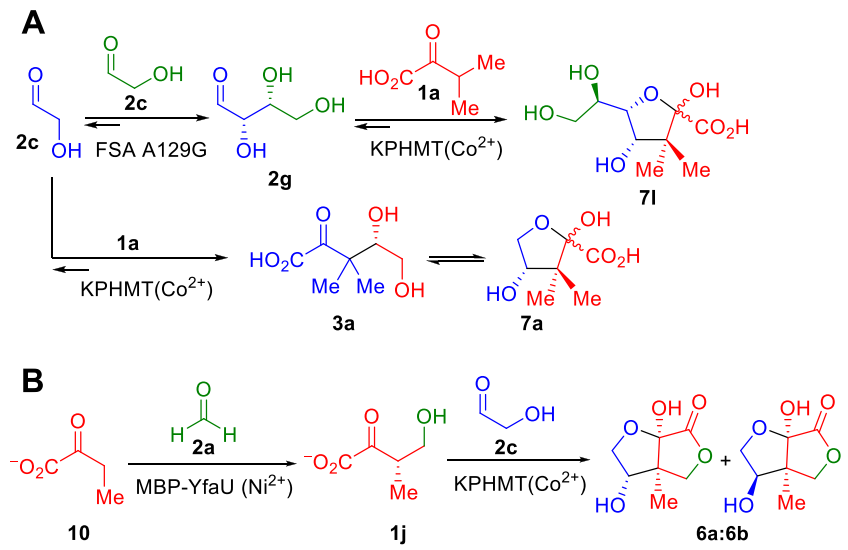

${ }^{a} \mathrm{MBP}-\mathrm{YfaU}=$ maltose binding protein fused to $\mathrm{YfaU} .{ }^{13 \mathrm{~b}}$

225 catalyzed by D-fructose-6-phosphate aldolase variant A129G 226 (FSA A129G) (Scheme 7A). ${ }^{24}$ Once $\mathbf{2 g}$ was produced, $\mathbf{1 a}$ and 227 KPHMT were added to the reaction mixture, yielding $7 \mathbf{l}$. 228 When the second step was carried out without removal of FSA 229 A129G, a significant amount of 7 a $(\sim 27 \%)$, from the addition 230 of $\mathbf{1 a}$ and $\mathbf{2 c}$, was detected. This side reaction was minimized $231(\sim 5 \%)$ by removing FSA A129G from the medium. This result 232 suggested that $2 \mathrm{c}$ was a better substrate than $2 \mathrm{~g}$ for KPHMT 233 and that it was transformed into $7 \mathbf{a}$ by KPHMT, via FSA234 catalyzed retro-aldol reaction of $\mathbf{2 g}$. By analogy, the synthesis 235 of the diastereomeric mixture $\mathbf{6 a}: \mathbf{6} \mathbf{b}$ was also carried out by a 236 one-pot two-step cascade (Scheme 7B). This comprised the 237 aldol addition of 2-oxobutyrate 10 to 2 a catalyzed by 2-keto-3238 deoxy-L-rhamnonate aldolase (YfaU, EC 4.1.2.53), generating 239 the nucleophile $\mathbf{1 j} .{ }^{13 \mathrm{~b}}$ Then, $\mathbf{2 c}$ and wild-type KPHMT were 240 added to furnish the diastereomeric mixture 6a:6b after 241 purification. In this case, there was no need to remove the $242 \mathrm{YfaU}$ since this pyruvate aldolase was not able to catalyze the 243 second aldol reaction, and the reaction with methanal was 244 virtually irreversible.

\section{$245 \square$ CONCLUSION}

246 In summary, we demonstrate the utility of the promiscuous 3247 methyl-2-oxobutanoate hydroxymethyltransferase (EC. 248 2.1.2.11) (KPHMT), for the creation of quaternary carbon 249 centers using a structurally diverse array of 3,3-disubstituted 2- oxoacid nucleophiles and aldehyde substrates. The biocatalytic 250 approach reported here benefits from a straightforward process 251 starting from diverse 2-oxoacid derivatives, obtained by well- 252 established and efficient chemical procedures. This method- 253 ology allows access to unprecedented 2-oxolactones, which can 254 be converted into $\alpha$-hydroxy- $\gamma$-butyrolactones by reduction of 255 the carbonyl group, 3-hydroxy acid derivatives, and ulosonic 256 acid type products, all of them bearing gem-dialkyl, gem- 257 cycloalkyl, and spirocyclic quaternary centers. To the best of 258 our knowledge, the aldol additions of 3,3-disubstituted 2- 259 oxoacid derivatives to aldehydes have not been performed with 260 other catalysts. For example: the enamine activation of 261 branched $\alpha, \alpha$-disubstituted carbonyl compounds via organo- 262 catalysis (e.g., proline and derivatives using typically 1-20 mol 263 \% compared with $\mathrm{KPHMT}\left(\mathrm{Co}^{2+}\right)$ catalysts employing 0.068264 $\mathrm{mol} \%$ ) is much less reactive with respect to those derived from 265 $\alpha$-monosubstituted carbonyl compounds, and therefore only 266 very strong electrophiles are able to react. ${ }^{3 a}$ Here, we are using 267 common aldehydes not specially activated and some even in 268 equilibrium with cyclic hemiketals in aqueous solution, e.g., D- 269 threose and D-erythrose. ${ }^{3 a}$ The present study expands the 270 portfolio of biocatalytic aldol reactions leading to unprece- 271 dented structures and offering new synthetic opportunities for 272 pharmaceutically relevant compounds and chiral precursors. 273 We anticipate a range of new applications by performing 274 further engineering of the KPHMT variants to render new 275 biocatalysts, efficient toward new substrate classes. 276

\section{ASSOCIATED CONTENT}

SI Supporting Information 278

The Supporting Information is available free of charge at 279 https://pubs.acs.org/doi/10.1021/jacs.0c09994. 280

Crystallographic data for structure 5c (CIF) 281

Experimental details, NMR spectra, and computational 282 models (PDF)

\section{3}

\section{AUTHOR INFORMATION}

284

Corresponding Author

Pere Clapés - Biological Chemistry Department, Instituto de 286 Quimica Avanzada de Cataluna, IQAC-CSIC, 08034 Barcelona, Spain; 이이이.org/0000-0001-5541-4794; 288 Email: pere.clapes@iqac.csic.es

Authors

Roser Marín-Valls - Biological Chemistry Department, Instituto 291 de Quimica Avanzada de Cataluña, IQAC-CSIC, 08034 Barcelona, Spain

Karel Hernández - Biological Chemistry Department, Instituto 294 de Quimica Avanzada de Cataluña, IQAC-CSIC, 08034295 Barcelona, Spain

Michael Bolte - Institut für Anorganische Chemie, J.-W.-Goethe- 297 Universität, Frankfurt/Main, Germany; 이이.org/0000- 298 0001-5296-6251

Teodor Parella - Servei de Ressonancia Magnetica Nuclear, 300 Universitat Autònoma de Barcelona, 08193 Bellaterra, Spain; 301 (1) orcid.org/0000-0002-1914-2709

Jesús, Joglar - Biological Chemistry Department, Instituto de 303 Quimica Avanzada de Cataluña, IQAC-CSIC, 08034 Barcelona, Spain

Jordi Bujons - Biological Chemistry Department, Instituto de 306 Quimica Avanzada de Cataluña, IQAC-CSIC, 08034 Barcelona, Spain

(2)

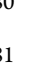

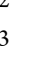


309 Complete contact information is available at:

310 https://pubs.acs.org/10.1021/jacs.0c09994

\section{Author Contributions}

$312{ }^{\perp}$ R.M.-V. and K.H. contributed equally. The manuscript was 313 written through contributions of all authors. All authors have 314 given approval to the final version of the manuscript.

315 Notes

316 The authors declare no competing financial interest.

\section{ACKNOWLEDGMENTS}

318 This project has received funding from the Ministerio de 319 Ciencia e Innovación (MICIN), the Fondo Europeo de 320 Desarrollo Regional (FEDER) (grant RTI2018-094637-B-I00 321 to P.C. and PGC2018-095808-B-I00 to T.P.), and Programa322 ción Conjunta Internacional (PCI2018-092937), through the 323 initiative ERA CoBioTech (Tralaminol). The authors grate324 fully acknowledge the "Consorci de Serveis Universitaris de 325 Catalunya" (CSUC) for allowing the use of its software and 326 hardware resources.

\section{REFERENCES}

328 (1) (a) Büschleb, M.; Dorich, S.; Hanessian, S.; Tao, D.; Schenthal, 329 K. B.; Overman, L. E. Synthetic Strategies toward Natural Products 330 Containing Contiguous Stereogenic Quaternary Carbon Atoms. 331 Angew. Chem., Int. Ed. 2016, 55 (13), 4156-4186. (b) Fuji, K. 332 Asymmetric creation of quaternary carbon centers. Chem. Rev. 1993, 33393 (6), 2037-2066. (c) Feng, J.; Holmes, M.; Krische, M. J. Acyclic 334 Quaternary Carbon Stereocenters via Enantioselective Transition 335 Metal Catalysis. Chem. Rev. 2017, 117 (19), 12564-12580. (d) Ding, 336 H. X.; Leverett, C. A.; Kyne, R. E.; Liu, K. K. C.; Fink, S. J.; Flick, A. 337 C.; O'Donnell, C. J. Synthetic approaches to the 2013 new drugs. 338 Bioorg. Med. Chem. 2015, 23 (9), 1895-1922. (e) Stockdale, T. P.; 339 Williams, C. M. Pharmaceuticals that contain polycyclic hydrocarbon 340 scaffolds. Chem. Soc. Rev. 2015, 44 (21), 7737-7763. (f) Newman, D. 341 J.; Cragg, G. M. Natural Products as Sources of New Drugs from 1981 342 to 2014. J. Nat. Prod. 2016, 79 (3), 629-661. (g) Li, Y.; Han, J.; Luo, 343 H.; An, Q.; Cao, X.-P.; Li, B. Access to Benzylic Quaternary Carbons 344 from Aromatic Ketones. Org. Lett. 2019, 21 (15), 6050-6053. 345 (h) Hu, P.; Chi, H. M.; DeBacker, K. C.; Gong, X.; Keim, J. H.; Hsu, 346 I. T.; Snyder, S. A. Quaternary-centre-guided synthesis of complex 347 polycyclic terpenes. Nature 2019, 569 (7758), 703-707. (i) Yoshi348 mura, F.; Itoh, R.; Torizuka, M.; Mori, G.; Tanino, K. Asymmetric 349 Total Synthesis of Brasilicardins. Angew. Chem., Int. Ed. 2018, 57 (52), 350 17161-17167. (j) Romanens, A.; Bélanger, G. Preparation of 351 Conformationally Restricted $\beta 2,2$ - and $\beta 2,2,3$-Amino Esters and 352 Derivatives Containing an All-Carbon Quaternary Center. Org. Lett. 353 2015, 17 (2), 322-325.

354 (2) (a) Lovering, F.; Bikker, J.; Humblet, C. Escape from Flatland: 355 Increasing Saturation as an Approach to Improving Clinical Success. J. 356 Med. Chem. 2009, 52 (21), 6752-6756. (b) Liu, Y.; Han, S.-J.; Liu, 357 W.-B.; Stoltz, B. M. Catalytic enantioselective construction of 358 quaternary stereocenters: assembly of key building blocks for the 359 synthesis of biologically active molecules. Acc. Chem. Res. 2015, 48 360 (3), 740-751.

361 (3) (a) Vetica, F.; de Figueiredo, R. M.; Orsini, M.; Tofani, D.; 362 Gasperi, T. Recent Advances in Organocatalytic Cascade Reactions 363 toward the Formation of Quaternary Stereocenters. Synthesis 2015, 47 364 (15), 2139-2184. (b) Marek, I.; Minko, Y.; Pasco, M.; Mejuch, T.; 365 Gilboa, N.; Chechik, H.; Das, J. P. All-Carbon Quaternary Stereogenic 366 Centers in Acyclic Systems through the Creation of Several C-C 367 Bonds per Chemical Step. J. Am. Chem. Soc. 2014, 136 (7), 2682368 2694. (c) Wang, B.; Tu, Y. Q. Stereoselective Construction of 369 Quaternary Carbon Stereocenters via a Semipinacol Rearrangement 370 Strategy. Acc. Chem. Res. 2011, 44 (11), 1207-1222. (d) Shimizu, M. 371 Construction of Asymmetric Quaternary Carbon Centers with High
Enantioselectivity. Angew. Chem., Int. Ed. 2011, 50 (27), 5998-6000. 372 (e) Sun, X.; Frimpong, K.; Tan, K. L. Synthesis of Quaternary Carbon 373 Centers via Hydroformylation. J. Am. Chem. Soc. 2010, 132 (34), 374 11841-11843. (f) Sklute, G.; Amsallem, D.; Shabli, A.; Varghese, J. 375 P.; Marek, I. Four-Component Reactions for a New Diastereoselective 376 Synthesis of Chiral Quaternary Centers. J. Am. Chem. Soc. 2003, 125377 (39), 11776-11777. (g) Li, Y.; Xu, S. Transition-Metal-Catalyzed C- 378 $\mathrm{H}$ Functionalization for Construction of Quaternary Carbon Centers. 379 Chem. - Eur. J. 2018, 24 (61), 16218-16245. (h) Cozzi, P. G.; Hilgraf, 380 R.; Zimmermann, N. Enantioselective Catalytic Formation of 381 Quaternary Stereogenic Centers. Eur. J. Org. Chem. 2007, 2007382 (36), 5969-5994. (i) Christoffers, J.; Mann, A. Enantioselective 383 Construction of Quaternary Stereocenters. Angew. Chem., Int. Ed. 384 2001, 40 (24), 4591-4597. (j) Yamago, S.; Machii, D.; Nakamura, E. 385 Simple diastereoselectivity of the aldol reaction of persubstituted 386 enolates. Stereoselective construction of quaternary centers. J. Org. 387 Chem. 1991, 56 (6), 2098-2106. (k) Fujii, K.; Mitsudo, K.; Mandai, 388 H.; Korenaga, T.; Suga, S. Enantioselective Acyl Migration Reactions 389 of Furanyl Carbonates with Chiral DMAP Derivatives. Chem.-Eur. J. 390 2019, 25 (9), 2208-2212. (1) Minko, Y.; Marek, I. Stereodefined 391 acyclic trisubstituted metal enolates towards the asymmetric 392 formation of quaternary carbon stereocentres. Chem. Commun. 393 2014, 50 (84), 12597-12611. (m) Das, J. P.; Marek, I. 394 Enantioselective synthesis of all-carbon quaternary stereogenic centers 395 in acyclic systems. Chem. Commun. 2011, 47 (16), 4593-4623. 396

(4) Martín Castro, A. M. Claisen Rearrangement over the Past Nine 397 Decades. Chem. Rev. 2004, 104 (6), 2939-3002. 398

(5) Corey, E. J. Catalytic Enantioselective Diels-Alder Reactions: 399 Methods, Mechanistic Fundamentals, Pathways, and Applications. 400 Angew. Chem., Int. Ed. 2002, 41 (10), 1650-1667.

(6) (a) Zhuo, C.-X.; Zheng, C.; You, S.-L. Transition-Metal- 402 Catalyzed Asymmetric Allylic Dearomatization Reactions. Acc. Chem. 403 Res. 2014, 47 (8), 2558-2573. (b) Trost, B. M.; Debien, L. 404 Palladium-Catalyzed Trimethylenemethane Cycloaddition of Olefins 405 Activated by the $\sigma$-Electron-Withdrawing Trifluoromethyl Group. J. 406 Am. Chem. Soc. 2015, 137 (36), 11606-11609. (c) Peifer, M.; Berger, 407 R.; Shurtleff, V. W.; Conrad, J. C.; MacMillan, D. W. C. A General 408 and Enantioselective Approach to Pentoses: A Rapid Synthesis of PSI- 409 6130, the Nucleoside Core of Sofosbuvir. J. Am. Chem. Soc. 2014, 136410 (16), 5900-5903. (d) Wu, C.-Y.; Xu, M.-H. Palladium-Catalyzed 411 Highly Enantioselective Arylation of Cyclic N-Sulfonyl $\alpha$-Ketimino 412 Esters towards the Synthesis of $\alpha$-Quaternary Chiral Amino Acid 413 Derivatives. ChemCatChem 2020, 12 (4), 1129-1133.

(7) (a) Tian, L.; Luo, Y.-C.; Hu, X-O; Xu, P.-F. Recent 415 Developments in the Synthesis of Chiral Compounds with 416 Quaternary Centers by Organocatalytic Cascade Reactions. Asian J. 417 Org. Chem. 2016, 5 (5), 580-607. (b) Mase, N.; Tanaka, F.; Barbas, 418 C. F., III Synthesis of $\beta$-Hydroxyaldehydes with Stereogenic 419 Quaternary Carbon Centers by Direct Organocatalytic Asymmetric 420 Aldol Reactions. Angew. Chem., Int. Ed. 2004, 43 (18), 2420-2423. 421 (8) (a) Fitzpatrick, D. E.; Battilocchio, C.; Ley, S. V. Enabling 422 Technologies for the Future of Chemical Synthesis. ACS Cent. Sci. 423 2016, 2 (3), 131-138. (b) Ley, S. V.; Baxendale, I. R. New tools and 424 concepts for modern organic synthesis. Nat. Rev. Drug Discovery 2002, 425 1 (8), 573-586.

(9) (a) Schmidt, N. G.; Eger, E.; Kroutil, W. Building Bridges: 427 Biocatalytic C-C-Bond Formation toward Multifunctional Products. 428 ACS Catal. 2016, 6 (7), 4286-4311. (b) Clapés, P., Recent Advances 429 in Enzyme-Catalyzed Aldol Addition Reactions. In Green Biocatalysis; 430 Patel, R. N., Ed.; John Wiley \& Sons, Inc: Hoboken, NJ, 2016; pp 431 267-306. (c) Clapés, P., Aldol Reactions. In Biocatalysis in Organic 432 Synthesis; Faber, K., Fessner, W.-D., Turner, N. J., Eds.; Georg Thieme 433 Verlag KG:: Stuttgart (Germany), 2015; Vol. 2, pp 31-92. (d) Müller, 434 M. Recent Developments in Enzymatic Asymmetric C-C Bond 435 Formation. Adv. Synth. Catal. 2012, 354 (17), 3161-3174. (e) Clapés, 436 P.; Garrabou, X. Current Trends in Asymmetric Synthesis With 437 Aldolases. Adv. Synth. Catal. 2011, 353 (13), 2263-2283. 438

(10) Sheldon, R. A.; Woodley, J. M. Role of Biocatalysis in 439 Sustainable Chemistry. Chem. Rev. 2018, 118 (2), 801-838. 440 
441 (11) (a) Coelho, P. S.; Brustad, E. M.; Kannan, A.; Arnold, F. H. 442 Olefin Cyclopropanation via Carbene Transfer Catalyzed by 443 Engineered Cytochrome P450 Enzymes. Science 2013, 339 (6117), 444 307-310. (b) Dick, M.; Sarai, N. S.; Martynowycz, M. W.; Gonen, T.; 445 Arnold, F. H. Tailoring Tryptophan Synthase TrpB for Selective 446 Quaternary Carbon Bond Formation. J. Am. Chem. Soc. 2019, 141 447 (50), 19817-19822. (c) Gao, Y.; Honzatko, R. B.; Peters, R. J. 448 Terpenoid synthase structures: a so far incomplete view of complex 449 catalysis. Nat. Prod. Rep. 2012, 29 (10), 1153-1175. (d) Hammer, S. 450 C.; Syrén, P.-O.; Seitz, M.; Nestl, B. M.; Hauer, B. Squalene hopene 451 cyclases: highly promiscuous and evolvable catalysts for stereo452 selective CC and CX bond formation. Curr. Opin. Chem. Biol. 2013, 45317 (2), 293-300.

454 (12) (a) Jones, C. E.; Brook, J. M.; Buck, D.; Abell, C.; Smith, A. G. 455 Cloning and Sequencing of the Escherichia coli panB Gene, which 456 Encodes Ketopantoate Hydroxymethyltransferase, and Overexpres457 sion of the Enzyme. J. Bacteriol. 1993, 175 (7), 2125-2130. 458 (b) Powers, S. G.; Snell, E. E. Ketopantoate hydroxymethyltransfer459 ase. II. Physical, catalytic, and regulatory properties. J. Biol. Chem. 460 1976, 251 (12), 3786-3793.

461 (13) (a) Sugantino, M.; Zheng, R.; Yu, M.; Blanchard, J. S. 462 Mycobacterium tuberculosis Ketopantoate Hydroxymethyltransferase: 463 Tetrahydrofolate-Independent Hydroxymethyltransferase and Enoli464 zation Reactions with $\alpha$-Keto Acids $\dagger$. Biochemistry 2003, 42 (1), 191465 199. (b) Marín-Valls, R.; Hernández, K.; Bolte, M.; Joglar, J.; Bujons, 466 J.; Clapés, P. Chemoenzymatic Hydroxymethylation of Carboxylic 467 Acids by Tandem Stereodivergent Biocatalytic Aldol Reaction and 468 Chemical Decarboxylation. ACS Catal. 2019, 9 (8), 7568-7577.

469 (14) Chaudhuri, B. N.; Sawaya, M. R.; Kim, C.-Y.; Waldo, G. S.; 470 Park, M. S.; Terwilliger, T. C.; Yeates, T. O. The Crystal Structure of 471 the First Enzyme in the Pantothenate Biosynthetic Pathway, 472 Ketopantoate Hydroxymethyltransferase, from M. tuberculosis. 473 Structure 2003, 11 (7), 753-764.

474 (15) von Delft, F.; Inoue, T.; Saldanha, S. A.; Ottenhof, H. H.; 475 Schmitzberger, F.; Birch, L. M.; Dhanaraj, V.; Witty, M.; Smith, A. G.; 476 Blundell, T. L.; Abell, C. Structure of E. coli Ketopantoate 477 Hydroxymethyl Transferase Complexed with Ketopantoate and $478 \mathrm{Mg} 2+$, Solved by Locating 160 Selenomethionine Sites. Structure 479 2003, 11 (8), 985-996.

480 (16) (a) Chen, F.; Topf, C.; Radnik, J.; Kreyenschulte, C.; Lund, H.; 481 Schneider, M.; Surkus, A.-E.; He, L.; Junge, K.; Beller, M. Stable and 482 Inert Cobalt Catalysts for Highly Selective and Practical Hydro483 genation of $\mathrm{C} \equiv \mathrm{N}$ and $\mathrm{C}=\mathrm{O}$ Bonds. J. Am. Chem. Soc. 2016, 138 (28), 484 8781-8788. (b) Erathodiyil, N.; Gu, H.; Shao, H.; Jiang, J.; Ying, J. Y. 485 Enantioselective hydrogenation of $\alpha$-ketoesters over alkaloid-modified 486 platinum nanowires. Green Chem. 2011, 13 (11), 3070-3074. 487 (c) Nakamura, K.; Kondo, S.-i.; Kawai, Y.; Ohno, A. Asymmetric 488 reduction of ketopantolactone by baker's yeast. Tetrahedron: 489 Asymmetry 1993, 4 (6), 1253-1254. (d) Salinas, Y.; Oliart, R. M.; 490 Ramírez-Lepe, M.; Navarro-Ocaña, A.; Valerio-Alfaro, G. Synthesis of 491 chiral $\alpha$-hydroxy amides by two sequential enzymatic catalyzed 492 reactions. Appl. Microbiol. Biotechnol. 2007, 75 (2), 297-302.

493 (17) (a) Bourgeois, F.; Medlock, J. A.; Bonrath, W.; Sparr, C. 494 Catalyst Repurposing Sequential Catalysis by Harnessing Regenerated 495 Prolinamide Organocatalysts as Transfer Hydrogenation Ligands. Org. 496 Lett. 2020, 22 (1), 110-115. (b) Sanyal, I.; Barman, P. D.; Banerjee, 497 A. K. Stereoselective synthesis of higher homologues of pantolactone 498 from (R)-glyceraldehyde acetonide. Tetrahedron Lett. 2015, 56 (6), 499 789-792. (c) Evans, D. A.; Wu, J.; Masse, C. E.; MacMillan, D. W. C. 500 A General Method for the Enantioselective Synthesis of Pantolactone 501 Derivatives. Org. Lett. 2002, 4 (20), 3379-3382. (d) Poll, T.; 502 Sobczak, A.; Hartmann, H.; Helmchen, G. Diastereoface-discrim503 inative metal coordination in asymmetric synthesis: D-pantolactone as 504 practical chiral auxiliary for Lewis acid catalyzed Diels-Alder reactions. 505 Tetrahedron Lett. 1985, 26 (26), 3095-3098. (e) Hajare, A. K.; 506 Ravikumar, V.; Khaleel, S.; Bhuniya, D.; Reddy, D. S. Synthesis of 507 Molluscicidal Agent Cyanolide A Macrolactone from D-(-)-Pan508 tolactone. J. Org. Chem. 2011, 76 (3), 963-966. (f) Eggersdorfer, M.; 509 Laudert, D.; Létinois, U.; McClymont, T.; Medlock, J.; Netscher, T.;
Bonrath, W. One Hundred years of vitamins-A success story of the 510 natural sciences. Angew. Chem., Int. Ed. 2012, 51 (52), 12960-12990. 511 (g) Athawale, P. R.; Kumari, N.; Dandawate, M. R.; Kashinath, K.; 512 Srinivasa Reddy, D. Synthesis of Chiral Tetrahydrofuran Building 513 Blocks from Pantolactones: Application in the Synthesis of 514 Empagliflozin and Amprenavir Analogs. Eur. J. Org. Chem. 2019, 515 2019 (30), 4805-4810. (h) Takao, K.-i.; Kai, H.; Yamada, A.; 516 Fukushima, Y.; Komatsu, D.; Ogura, A.; Yoshida, K. Total Syntheses 517 of (+)-Aquatolide and Related Humulanolides. Angew. Chem., Int. Ed. 518 2019, 58 (29), 9851-9855. (i) Kuethe, J. T.; Humphrey, G. R.; 519 Journet, M.; Peng, Z.; Childers, K. G. Asymmetric Synthesis of a 520 Potent HIV-1 Integrase Inhibitor. J. Org. Chem. 2016, 81 (21), 521 10256-10265.

(18) (a) Gordon, E. M.; Duncton, M. A. J.; Gallop, M. A. Orally 523 Absorbed Derivatives of the $\beta$-Lactamase Inhibitor Avibactam. Design 524 of Novel Prodrugs of Sulfate Containing Drugs. J. Med. Chem. 2018, 525 61 (22), 10340-10344. (b) James, K.; Palmer, M. J. Gem-cycloalkyl 526 substituted thiol inhibitors of neutral endopeptidase 24.11. Synthesis 527 via nucleophilic opening of 2,2-spiro- $\beta$-lactones. Bioorg. Med. Chem. 528 Lett. 1993, 3 (5), 825-830. (c) Szostak, M.; Spain, M.; Procter, D. J. 529 Selective synthesis of 3-hydroxy acids from Meldrum's acids using 530 $\mathrm{SmI}_{2}-\mathrm{H}_{2}$ O. Nat. Protoc. 2012, 7 (5), 970-977. (d) Khan, M. A. 531 Preparation of spiro-lactam NMDA receptor modulators for the 532 treatment of depression and related disorders. WO2018026763A1, 533 2018. (e) Cheruvallath, Z.; Green, J.; Johnson, B.; Schleicher, K.; Sun, 534 H.; Tang, M. Preparation of piperidinyl 3-(aryloxy)propanamides and 535 3-(aryloxy)propanoates as SSTR4 modulators. WO2019169153A1, 536 2019. (f) Lee, D.-Y.; Hou, Y.-C.; Yang, J.-S.; Lin, H.-Y.; Chang, T.-Y.; 537 Lee, K.-H.; Kuo, S.-C.; Hsieh, M.-T. Synthesis, Anticancer Activity, 538 and Preliminary Pharmacokinetic Evaluation of 4,4-Disubstituted 539 Curcuminoid 2,2-bis(Hydroxymethyl)Propionate Derivatives. Mole- 540 cules 2020, 25 (3), 479. (g) Hewawasam, P.; Lopez, O. D.; Tu, Y.; 541 Wang, A. X.; Xu, N.; Kadow, J. F.; Meanwell, N. A.; Gupta, S. V. S. A. 542 K.; Kumar, I. J. G.; Punugupati, S. K.; Belema, M. Preparation of 543 substituted azoles and their use as hepatitis $\mathrm{C}$ virus inhibitors. 544 US20150023913A1, 2015. (h) Boeckman, R. K.; Miller, J. R. Direct 545 Enantioselective Organocatalytic Hydroxymethylation of Aldehydes 546 Catalyzed by $\alpha, \alpha$-Diphenylprolinol Trimethylsilyl Ether. Org. Lett. 547 2009, 11 (20), 4544-4547.

(19) (a) Wei, D.; Huang, X.; Zeng, J.; Deng, S.; Xu, J. Facile 549 synthesis of a castor oil-based hyperbranched acrylate oligomer and its 550 application in UV-curable coatings. J. Appl. Polym. Sci. 2020, 137 (36), 551 49054. (b) García-Gallego, S.; Andrén, O. C. J.; Malkoch, M. 552 Accelerated Chemoselective Reactions to Sequence-Controlled 553 Heterolayered Dendrimers. J. Am. Chem. Soc. 2020, 142 (3), 1501- 554 1509. (c) Zhang, X.; Dai, Y.; Dai, G. Advances in amphiphilic 555 hyperbranched copolymers with an aliphatic hyperbranched 2,2- 556 bis(methylol)propionic acid-based polyester core. Polym. Chem. 2020, 557 11 (5), 964-973.

(20) (a) Ishizawa, K.; Majima, S.; Wei, X.-F.; Mitsunuma, H.; 559 Shimizu, Y.; Kanai, M. Copper(I)-Catalyzed Stereodivergent Prop- 560 argylation of N-Acetyl Mannosamine for Protecting Group Minimal 561 Synthesis of C3-Substituted Sialic Acids. J. Org. Chem. 2019, 84 (17), 562 10615-10628. (b) De Meo, C.; Jones, B. T. Chemical Synthesis of 563 Glycosides of $N$-Acetylneuraminic Acid. In Adv. Carbohydr. Chem. 564 Biochem.; Baker, D. C., Ed.; Academic Press: 2018; Vol. 75, pp 215- 565 316.

(21) (a) Varki, A. Diversity in the sialic acids. Glycobiology 1992, 2567 (1), 25-40. (b) Varki, A. Glycan-based interactions involving 568 vertebrate sialic-acid-recognizing proteins. Nature (London, U. K.) 569 2007, 446 (7139), 1023-1029.

570

(22) Wenzel, T. J. Discrimination of chiral compounds using NMR 571 spectroscopy; John Wiley \& Sons: 2007.

(23) Aberhart, D. J.; Russell, D. J. Steric course of ketopantoate 573 hydroxymethyltransferase in E. coli. J. Am. Chem. Soc. 1984, 106 (17), 574 $4902-4906$.

(24) (a) Szekrenyi, A.; Garrabou, X.; Parella, T.; Joglar, J.; Bujons, J.; 576 Clapés, P. Asymmetric assembly of aldose carbohydrates from 577 formaldehyde and glycolaldehyde by tandem biocatalytic aldol 578 
579 reactions. Nat. Chem. 2015, 7 (9), 724-729. (b) Szekrenyi, A.; Soler, 580 A.; Garrabou, X.; Guerard-Helaine, C.; Parella, T.; Joglar, J.; Lemaire, 581 M.; Bujons, J.; Clapés, P. Engineering the Donor Selectivity of D582 Fructose-6-Phosphate Aldolase for Biocatalytic Asymmetric Cross583 Aldol Additions of Glycolaldehyde. Chem. - Eur. J. 2014, 20 (39), 584 12572-12583. 